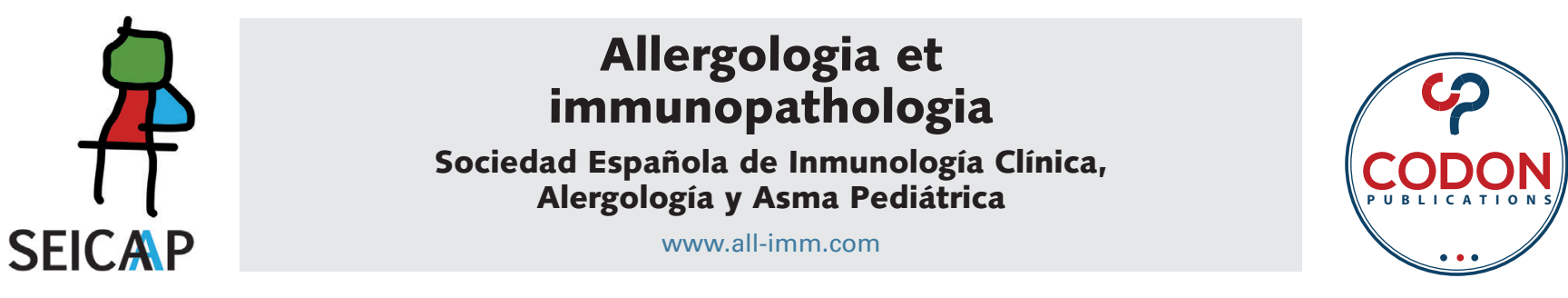

\title{
Combination therapy of specific aeroallergens immunotherapy and omalizumab, in children with severe asthma
}

\section{Laura Valdesoiro-Navarrete ${ }^{\mathrm{a}, \mathrm{b} *}$, María Esther León ${ }^{\mathrm{a}}$, Marcos Rodríguez $^{\mathrm{a}}$, Martina Indiveric, Roser Ayats ${ }^{a}$, Helena Larramona ${ }^{a}$, Miguel García González ${ }^{a}$, Òscar Asensio de la Cruz ${ }^{a}$, Montserrat Bosque García ${ }^{a}$}

aPaediatric Allergies, Immunology and Pneumology Unit, Paediatric Medicine Service, Parc Tauli University Hospital of Sabadell, Barcelona, Spain

'Institut d'Investigació i Innovació Parc Taulí, Sabadell, Spain

'Sección de Inmunoalergia, Hospital TJ.Schestakow, San Rafael, Argentina

Received 19 June 2021; Accepted 30 December 2021

Available online 1 March 2022

\section{KEYWORDS}

children;

omalizumab;

severe asthma;

specific aeroallergen

immunotherapy

\begin{abstract}
Background: In most cases, severe asthma in children has an allergic etiology, but allergen-specific immunotherapy (AIT) is contraindicated.

Objective: This study aimed at analyzing the safety and efficacy of AIT in patients with severe asthma treated with omalizumab (OM).

Methods: A descriptive real-life study was carried out by reviewing medical records. Effectiveness was measured by the degree of control (CAN questionnaire), number of hospitalizations per year, number of exacerbations per year, and maintenance treatment and lung function (FEV1). Some adverse reactions occurred (AAI-EAACI-WAO guidelines).

Results: The retrospective study included 29 patients up to 18 years of age with severe asthma with OM plus AIT treatment. AIT treatment was started in a cluster schedule when patients treated with OM achieved disease control. Before starting AIT, patients were treated with OM for 1 year for achieving asthmatic control. AIT to mites (51\%), Alternaria (37.9\%), or pollens (10.3\%) was administered. After one year with OM plus AIT,statistically significant differences in CAN scores and FEV1 measures were observed $(P<0.001)$. No patients under treatment with OM plus AIT required hospital admission. During the clustering schedule, only $3 / 64$ doses showed systemic adverse reactions. During the AIT maintenance treatment, 348 doses were administered, with no significant adverse reactions.

Conclusion: In this population-based study in children with severe asthma, the combined treatment with OM plus AIT was safe and effective. This strategy allows these pediatric patients to be safely treated with AIT.

(c) 2022 Codon Publications. Published by Codon Publications.
\end{abstract}

${ }^{*}$ Corresponding author: Laura Valdesoiro-Navarrete. Paediatric Allergies, Immunology and Pneumology Unit, Paediatric Medicine Service, Parc Taulí University Hospital of Sabadell, Taulí s/n, E-08208 Sabadell, Barcelona, Spain. Email address: Ivaldesoiro@gmail.com 


\section{Introduction}

A high degree of morbidity and mortality is associated with severe asthma in children. It is characterized by controlled symptoms with high doses of inhaled or oral corticosteroids or by uncontrolled asthma symptoms despite such therapy. In addition, this condition exerts a substantial burden on patients' care, ${ }^{1-3}$ their families, and the health service. Unscheduled medical visits and even the use of emergency rooms and hospital admissions are often required.

In most cases, severe asthma in children has an allergic etiology. Specific allergen immunotherapy (AIT) is the only immunomodulatory treatment available to treat allergic disease. ${ }^{4,5}$ But AIT is ineffective in severe uncontrolled asthma.

Omalizumab $(\mathrm{OM})$ is a biological treatment approved for moderate-to-severe persistent allergic asthma management $^{7}$ in patients of at least 6 years of age. Some authors have obtained successful results from the combined therapy with specific (AIT) and OM for allergic rhinitis, asthma, allergy to hymenoptera venom, and food allergy.

However, there is currently little clinical experience with combined treatment with AIT and OM in severe pediatric asthma. After controlling asthma with OM, AIT can be safely and effectively administered. ${ }^{8-10}$ This study aimed to analyze the safety and effectiveness of AIT in pediatric patients with severe asthma receiving OM treatment.

\section{Methods}

This was a retrospective, descriptive, real-life, postauthorization study with a different design than the prospective follow-up (EPA-OD) according to the evaluation of the Spanish Drug Agency (AEM, for its initials in Spanish). This study has been approved by the ethics committee of our hospital and carried out by reviewing the medical records.

All clinical records of patients up to 18 years of age, with a diagnosis of severe allergic asthma and GINA stage 5 receiving combined treatment with aeroAITand OM from 2015 to 2019 were included. Inclusion/exclusion criteria are shown in Table 1.

We guarantee that all the information in the study will be treated as stipulated by regulation 2016/679 of the

Table 1 Inclusion and exclusion criteria.

Inclusion criteria

Patients up to 18 years of age under follow-up at our hospital.

Diagnosed with severe allergic asthma and under treatment with omalizumab.

Sensitization to mites, Alternaria or pollen (prick test with

$>3 \mathrm{~mm}$ or specific immunoglobulin $\mathrm{E}$ of $>0.35 \mathrm{KU} / \mathrm{L}$ ).

Under treatment with immunotherapy associated with omalizumab for at least 1 year.

Exclusion criteria

Loss of follow-up or inability to collect data from patients' medical history.
European Parliament and of the Council of April 27, 2016, on data protection (GDPR), and Organic Law 3/2018 of December 5 , on the protection of personal data and guarantee of digital rights. Data were obtained retrospectively from patients' medical histories.

The primary endpoint to evaluate safety was the number of local and systemic adverse reactions to immunotherapy classified according to the 2010 AAI-EAACI-WAO guidelines..$^{11,12}$

Effectiveness was measured by the degree of control (CAN questionnaire), number of hospitalizations per year, number of exacerbations per year, maintenance treatment needed, and lung function (FEV1).

Data on type of immunotherapy extract, allergens included, doses administered, age at treatment start, duration of OM treatment, AIT, sex, and other concomitant allergic diseases were collected.

CAN questionnaire scores were collected before starting treatment with $\mathrm{OM}$ and combined treatment with $\mathrm{OM}$ plus AIT and 1- and 2 years after combined treatment with OM plus AIT. Two determinations : one before treatment initiation with $O M$ and the other one- and two years after the combined treatment initiation, were made to evaluate the number of hospitalizations per year and of exacerbations per year.

Maintenance treatment needed (according to GEMA guidelines' therapeutic steps) and lung function (FEV1) were collected before starting OM and AIT and 1 year after combined treatment to evaluate effectiveness.

The administration of $\mathrm{OM}$ and the indication of AIT are regular practices in the treatment of asthma; for this reason, we request the ethics committee to make an exception to the requirement to obtain informed consent, according to the classification of our study by the Spanish drug agency.

\section{Statistical study}

Quantitative variables have been described using the mean and standard deviation for normal distribution and the median and 25th and 75th percentiles for nonnormal distribution. Qualitative variables were described using frequencies and percentages.

Inference on effectiveness was studied using repeated-measures analysis of variance (ANOVA) of CAN questionnaire scores. FEV1 values and maintenance treatment needed was used to describe the reduction in the number of exacerbations and hospitalizations before treatment with $O M$ and after 1 year with combined therapy with OM and ATI. The data were compared using Wilcoxon nonparametric test for paired data. For all analyses, $\mathrm{P}$ values $<0.05$ were considered statistically significant. Statistical analyses were performed with the IBM SPSS software Version 25 (IBM SPSS Statistics, Armonk, NY).

\section{Results}

The study included 29 patients, 21 (72.4\%) of whom were boys up to 18 years of age with severe asthma and treated 
with OM and AIT. Before starting AIT, they were treated with OM for 1 year to achieve asthma control.

Once their disease was controlled and remained that way after decreasing the maintenance treatment, AIT specific to mites or Alternaria in a cluster schedule was administered, depending on the sensitization they showed. AIT was administered subcutaneously at the daycare hospital, which was equipped for the treatment of allergic reactions and close to the emergency and intensive care units.

Patients' age at the start of treatment with $\mathrm{OM}$ and combined treatment with AIT and OM and duration of both therapies at the time of analysis are shown in Table 2.

The median immunoglobulin $\mathrm{E}$ value before treatment with $\mathrm{OM}$ was $719 \mathrm{IU} / \mathrm{mL}$ (p25 of $345 \mathrm{IU} / \mathrm{mL}$ and p75 of 1448 $\mathrm{IU} / \mathrm{mL}$ ).

Fifteen $(51.7 \%)$ patients received treatment with a mixed extract of Dermatophagoides pteronysinus and $D$. farinae, 11 (37.9\%) were treated with an Alternaria extract, and three $(10.3 \%)$ with a pollen extract.

All our patients had comorbidities associated with their severe asthma: 10 (34.4\%) had atopic dermatitis, 11 (37.9\%) had a food allergy, and 19 (65.5\%) had allergic rhinitis.

The following variables were collected: CAN questionnaire scores, lung function (FEV1), maintenance treatment needed, number of exacerbations, and number of hospital admissions to evaluate the effectiveness of the treatment.

We observed a decrease in the CAN questionnaire scores (Figure 1) and maintenance treatment (Figure 3) and an increase in FEV1 values (Figure 2) throughout the entire treatment, indicating efficacy in asthma control. When comparing these values using the repeated-measures ANOVA test, statistically significant differences were found, showing a decrease in the CAN questionnaire scores $(P<$ $0.001)$ and in the therapeutic maintenance step $(P<0.001)$, and an increase in FEV1 $(P<0.001)$ throughout the study period.

Comparisons (Table 3 ) between the CAN questionnaire scores before starting $\mathrm{OM}$ and 2 years after combined treatment, before starting AIT and 2 years after combined treatment, and after 1 year with OM plus AIT and at 2 years of treatment showed statistically significant differences $(P<0.001)$. All 29 patients required systemic corticosteroids before $\mathrm{OM}$ treatment, and none required any corticosteroids 1 year after the combined treatment. Comparisons (Table 4) between FEV1 measurements at the start of OM treatment, before the start of AIT, and 1 year after combined treatment (OM plus AIT) showed statistically significant differences $(P<0.001)$

The number of hospital admissions per year because of asthma decreased significantly. No patients receiving treatment with OM plus AIT for 2 years required hospital admission. When comparing these values using the Wilcoxon test for paired measures, statistically significant differences were found $(P<0.001)$.

Immunotherapy was administered in a cluster schedule. About 26 patients received treatment with polymerized extracts, and three were treated with depot extracts.

During this schedule, 64 doses of immunotherapy were administered, (52 (81.2\%) polymerized extracts and 12 $(18.8 \%)$ native extracts). Adverse reactions were seen in 10 administered doses and seven local reactions. Only three grade 3 (4.6\%) systemic reactions were reported(one urticaria and two bronchospasms). None of them required hospital admission and it the AIT was not discontinued.

During the AIT maintenance treatment, 348 doses were administered, and no significant adverse reactions were observed.

\section{Discussion}

This was a retrospective, real-life, observational study to review medical records in 29 children with severe asthma who received combined treatment with OM and AIT in our hospital. We observed statistically significant differences in the CAN questionnaire scores and FEV1 measures after 1 year with OM plus AIT $(P<0.001)$. No patients treated with OM plus AIT required hospital admission. During the clustering schedule, only $3 / 64$ doses showed systemic adverse reactions. During the AIT maintenance treatment, 348 doses were administered, and no significant adverse reactions were observed.

Most cases of severe asthma in the pediatric population are atopic asthma and sensitization to aeroallergens. However, AIT is currently inadvisable $e^{4,5}$ in patients with poorly controlled severe asthma because of the high risk
Table 2 Age at start of treatment and duration of treatments (years).

\begin{tabular}{lcc}
\hline $\mathrm{N}=29$ & $\begin{array}{c}\text { Mean }(\mathrm{min} ; \\
\text { max), years }\end{array}$ & $\begin{array}{c}\text { Standard } \\
\text { deviation }\end{array}$ \\
\hline Age at start of OM & $9(4 ; 16)$ & 3.6 \\
$\begin{array}{l}\text { Age at start of AIT } \\
\text { Duration of OM treatment }\end{array}$ & $10(5 ; 17)$ & 4 \\
$\begin{array}{l}\text { before starting AIT } \\
\text { Duration of combined }\end{array}$ & $2.5(1 ; 3)$ & 0.9 \\
treatment (OM+ ITA) & & 1.1 \\
Duration of OM treatment & $3.7(1 ; 8)$ & 1.6 \\
\hline
\end{tabular}

OM, omalizumab; AIT, allergen immunotherapy; Min, minimum; Max, maximum.

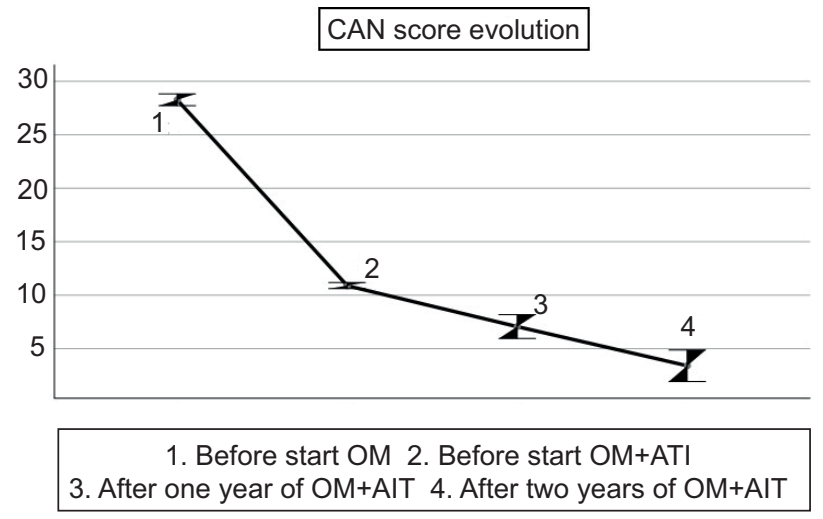

Figure 1 CAN questionnaire scores throughout the treatment. 


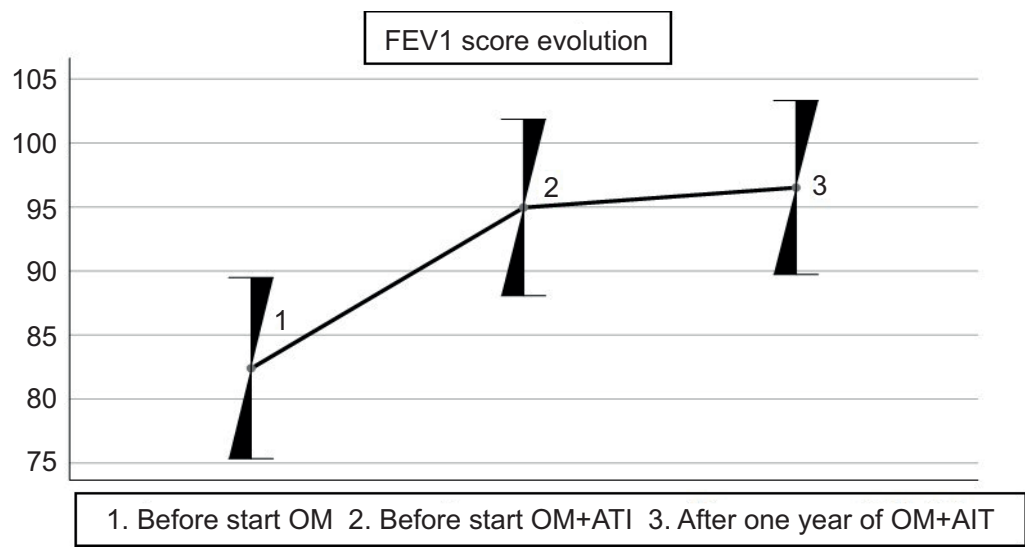

Figure $2 \mathrm{FEV}_{1}$ values throughout the treatment.

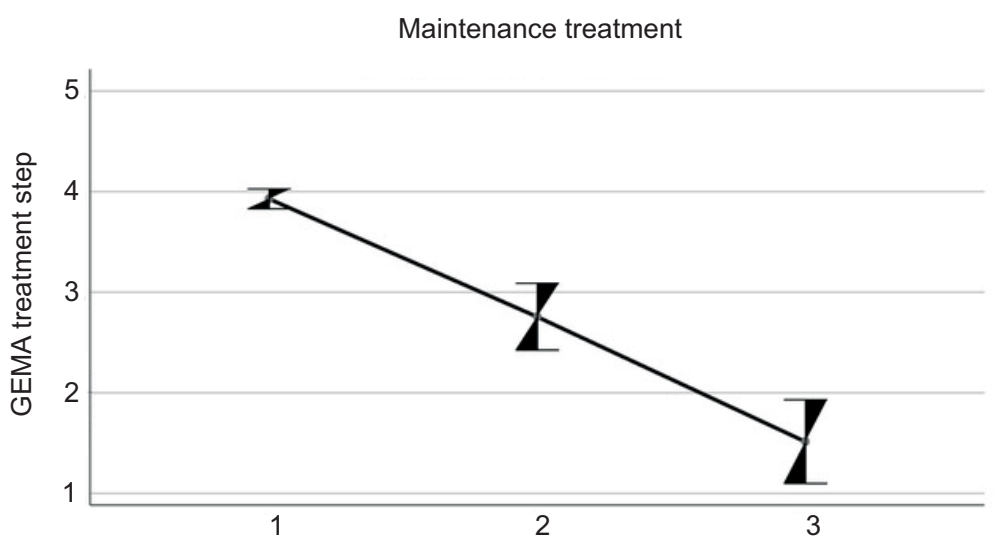

$\begin{array}{lll}\text { 1. Before start OM } & \text { 2. Before start OM+AIT } \quad 3 \text {. After one year of OM+AIT }\end{array}$

Figure 3 Maintenance treatment.

Table 3 Efficiency variables: CAN questionnaire (asthma control in children) score of $<9$.

\begin{tabular}{lccc}
\hline CAN questionnaire & Mean & p25-p75 & P value* $^{*}$ \\
\hline 1. Before start of OM & 28.2 & $27-29.5$ & \\
2. Before start of AIT & 10.9 & $9-11.5$ & \\
3. After one year of OM+AIT & 7.07 & $7-9$ & $<0.001$ \\
4. After two years of OM+AIT & 4 & $0-8$ & $<0.001$ \\
\hline *t-student. & & & \\
OM, omalizumab; AIT, allergen immunotherapy. &
\end{tabular}

for adverse effects. Previous studies have shown that AIT has better results in patients with severe allergic rhinitis, and the same can be expected with severe asthma. ${ }^{13,14}$ The evidence on the efficacy of AIT in severe asthma in children is quite limited because of the difficulties in conducting clinical trials in children and the contraindication of AIT for severe asthma.

There are few studies on severe asthma and immunotherapy in the pediatric population. In a study conducted by Tsai et al. ${ }^{15}$, 40 children aged 5 to 14 years with moderateto-severe asthma were randomly assigned to receive a mite
Table 4 Efficiency variables: FEV1 (L/s).

\begin{tabular}{lccl}
\hline Lung function - FEV $1 \%)$ & $\begin{array}{c}\text { Mean } \\
\mathrm{FEV}_{1}(\%)\end{array}$ & $\begin{array}{c}\mathrm{FEV}_{1}(\%) \\
(\mathrm{p} 25-\mathrm{p} 75)\end{array}$ & $\mathrm{P}^{*}$ value \\
\hline Before start of OM & 78 & $(65.5-97.5)$ & \\
Before start of AIT & 92 & $(81.5-105.8)$ & \\
After one year of OM+AIT & 96 & $(85-103)$ & $<0.001$ \\
\hline *t-student. & & &
\end{tabular}

extract subcutaneously. After 6 months of follow-up, no systemic reactions were recorded, and patients treated with immunotherapy improved their symptoms than those who did not receive this treatment $(P<0.01)$. This study only included patients with severe asthma that received treatment with OM (Table 5). But also observed the safety and improvement in those patients with severe asthma who underwent AIT plus OM therapy.

Only very few studies on the efficacy of combined therapy with OM and AIT in the treatment of severe asthma in children exist, with only some showing the safety and efficacy of OM before the treatment or in combined treatment in adult patients with severe allergic asthma, with the achievement of disease control and a decrease in the severity of the symptoms. ${ }^{16-18}$ We have observed similar 
Table 5 Efficacy variables: exacerbations/year.

\begin{tabular}{lccc}
\hline Clinical improvement & $\begin{array}{c}\text { Exacerbations/ } \\
\text { year }\end{array}$ & $\begin{array}{c}\text { Value } \\
(\mathrm{p} 25-\mathrm{p} 75)\end{array}$ & $\begin{array}{c}\mathrm{p} \\
\text { value }^{*}\end{array}$ \\
\hline Before start of OM & 6 & $5-7$ & \\
Before start of OM+ATI & 1 & $0-2$ & $<0.001$ \\
After one year of & None & & \\
OM+AIT & & & \\
\hline
\end{tabular}

*Wilcoxon test.

OM, omalizumab; AIT, allergen immunotherapy

results in our pediatric patients. In our experience, when patient stops $O M$, they are still symptom-free with immunotherapy. Unfortunately, our study did not aim to compare the duration of OM treatment with or without ATI. We stopped immunotherapy when the 4 years of treatment ended, and our patients remained under control with low doses of inhaled therapy. We believe that the efficacy of immunotherapy should be similar to patients with nonsevere asthma, but a longer follow-up is necessary to assess their long-term efficacy.

Massanari et al. ${ }^{19}$ published a multicenter, double-blind, randomized study in adult patients with symptomatic asthma to evaluate the effect of OM on the tolerability of AIT for 1-3 extracts and showed that the use of OM in patients with severe asthma was associated with fewer systemic allergic reactions to specific immunotherapy and facilitated reaching the maintenance dose of immunotherapy as observed in our pediatric patients, where all 29 reached the target immunotherapy doses without serious adverse events and improved asthma control.

Our safety results are consistent with those observed by Har and Jung Lee, ${ }^{20}$ published a retrospective safety study that only included the pediatric population and compared AIT, OM, and combined AIT plus OM treatments. Results indicated that the combined therapy with OM and AIT in children is safe and allows the administration of AIT. Only $2 / 29$ patients had a systemic reaction during the clustering schedule (2/64 doses administered), which resolved with oral or inhaled treatment. After 412 AIT doses were administrated, none of our severe asthma patients treated with $O M$ required adrenaline or hospitalization.

The results of our study were limited by the number of patients included and the retrospective design. But our results showed statistically significant differences in efficacy, and studies such as those conducted by Har et al. ${ }^{20}$ support the safety of the combined treatment. In our opinion, offering an immunotherapy option to our patients with severe allergic asthma is the correct option since it is the best treatment option for asthma controlled with OM.

\section{Conclusion}

In our population-based study in children with severe asthma, the combined treatment of omalizumab and AIT was safe and effective. This strategy gives pediatric patients with severe asthma an opportunity to be safely treated with AIT. Inducing a change in their immune response would change the severity phenotype, improve patients' quality of life, and prevent airway remodeling. Just as the studies carried out with adult patients, they can even raise the need to develop standardized protocols for this combined treatment to optimize the management of severe allergic asthma.

\section{References}

1. Lang A, Carlsen KH, Haaland G, Devulapalli CS, Munthe-Kaas M, Mowinckel $P$, et al.. Severe asthma in childhood: assessed in 10 year olds in a birth cohort study. Allergy. 2008;63(8):105460. http://dx.doi.org/10.1111/j.1398-9995.2008.01672.x

2. Fitzpatrick A, Moore W. Severe asthma phenotypes - How should they guide evaluation and treatment? J Allergy Clin Immunol Pract. 2017;5(4):901-8.http://dx.doi.org/10.1016/j. jaip.2017.05.015

3. Fleming L, Murray C, Bansal AT, Hashimoto S, Bisgaard H, Bush A, et al. The burden of severe asthma in childhood and adolescence: Results from the paediatric U-BIOPRED cohorts. Eur Respir J. 2015; 46:1322-33. http://dx.doi. org/10.1183/13993003.00780-2015

4. Alvaro-Lozano M, Akdis CA, Alviani C, Angier E, Arasi S, et al. EAACl allergen immunotherapy user's guide Pediatr Allergy Immunol. 2020;31(25):1--101. http://dx.doi.org/10.1111/pai. 13189

5. Pajno GB, Castagnoli R, Muraro A, Alvaro-Lozano M, Akdis CA, Akdis $M$, et al. Allergen immunotherapy for IgE-mediated food allergy: There is a measure in everything to a proper proportion of therapy. Pediatr Allergy Immunol. 2019;30(4):415-22. http://dx.doi.org/10.1111/pai.13042.

6. Roberts G, Pfaar O, Akdis CA, Ansotegui IJ, Durham SR, Gerth van Wijk $\mathrm{R}$, et al. EAACl guidelines on allergen immunotherapy: Allergic rhinoconjunctivitis. Allergy. 2018;73(4):765-98. http://dx.doi.org/10.1111/all.13317

7. Maglione M, Poeta M, Santamaria F. New drugs for pediatric asthma. Front Pediatr. 2019; 6:432. http://dx.doi.org/10.3389/ fped.2018.00432

8. Braido F, Corsico A, Rogkakou A, Ronzoni V, Baiardini I, Canonica GW. The relationship between allergen immunotherapy and omalizumab for treating asthma. Expert Rev Respir Med. 2015;, 9(2):129-34. http://dx.doi.org/10.1586/17476348.2 015.1000866

9. Licari A, Marseglia A, Caimmi S, Castagnoli R, Foiadelli T, Barberi S, Marseglia GL. Omalizumab in children. Paediatr Drugs. 2014;16(6):491-502. http://dx.doi.org/10.1007/s40272-014-0107-z.

10. Carrier C, Demoly P, Caimmi D. [Omalizumab and allergen immunotherapy: A clinical report and review of the literature]. Rev Mal Respir. 2019;36(2):191-6. French. http://dx.doi. org/10.1016/j.rmr.2018.03.006

11. Del Rodriguez RP, Vidal C, Just J, Tabar Al, Sanchez-Machin I, Eberle P, et al. The European Survey on Adverse Systemic Reactions in Allergen Immunotherapy (EASSI): A paediatric assessment. Pediatr Allergy Immunol. 2017;28(1):60-70. http://dx.doi.org/10.1111/pai.12660

12. Calderon MA, Vidal C, Rodriguez Del Rio P, Just J, Pfaar 0 , Tabar Al, et al. European Survey on Adverse Systemic Reactions in Allergen Immunotherapy (EASSI): A real-life clinical assessment. Allergy. 2017;72(3):462-72. http://dx.doi.org/10.1111/all.13066

13. Howarth P, Malling H-J, Molimard M, Devillier P. Analysis of allergen immunotherapy studies shows increased clinical efficacy in highly symptomatic patients. Allergy. 2012;67(3):321-7. http://dx.doi.org/10.1159/000452333

14. Schiappoli M, Ridolo E, Senna G, Alesina R, Antonicelli L, Asero $\mathrm{R}$, et al. A prospective Italian survey on the safety of subcutaneous immunotherapy for respiratory allergy. 
Clin Exp Allergy. 2009;39(10):1569-74. http://dx.doi. org/10.1111/j.1365-2222.2009.03286.X

15. Tsai T-C, Lu J-H, Chen S-J, Tang R-B. Clinical efficacy of house dust mite-specific immunotherapy in asthmatic children. Pediatr Neonatol. 2010;51:14-8. http://dx.doi.org/10.1016/ S1875-9572(10)60004-6

16. Lambert N, Guiddir T, Amat F, Just J. Pre-treatment by omalizumab allows allergen immunotherapy in children and young adults with severe allergic asthma. Pediatr Allergy Immunol. 2014;25(8):829-32. http://dx.doi.org/10.1111/pai.12306

17. Carrier C, Demoly P, Caimmi D. [Omalizumab and allergen immunotherapy: A clinical report and review of the literature]. Revue des Maladies Respiratoires. 2019;36(2):191-6. http://dx.doi.org/10.1016/j.rmr.2018.03.006
18. Dantzer JA, Wood RA. The use of omalizumab in allergen immunotherapy. Clin Exp Allergy. 2018;48(3):232-40. http:// dx.doi.org/10.1111/cea.13084

19. Massanari M, Nelson $H$, Casale $T$, Busse $W$, Kianifard $F$, Geba GP, et al. Effect of pretreatment with omalizumab on the tolerability of specific immunotherapy in allergic asthma. J Allergy Clin Immunol. 2010;125(2):383-9. http://dx.doi.org/ 10.1016/j.jaci.2009.11.022

20. Har D, Jung Lee M. Systemic reaction rates with omalizumab, subcutaneous immunotherapy, and combination therapy in children with allergic asthma. Allergy Asthma Proc. 2019;40:35-40. http://dx.doi.org/10.2500/aap.2019.40.4173 